\title{
INVESTIGAÇÃO DOS NÍVEIS DE RADIAÇÃO IONIZANTE NO SETOR DE DIAGNÓSTICO POR RAIOS-X DE UM AEROPORTO DO INTERIOR PAULISTA
}

\author{
Larissa Cristina Ederli Vissoto, Cássio Fabian Sarquis de Campos, Vitor José Bazzo.
}

Universidade do Oeste Paulista - UNOESTE, Curso Superior de Tecnologia em Radiologia, Presidente Prudente, SP.

\begin{abstract}
RESUMO
Radiações ionizantes são ondas eletromagnéticas ou partículas com alta energia capazes de produzir ionizações. Onde interação dessas ondas com a matéria desencadeará uma série de ionização. Dessa forma, podendo ocorrer efeitos biológicos de maior ou menor gravidade conforme o organismo ou tecido irradiado. Este trabalho teve por objetivo aferir os níveis de radiação ionizante emitidas por aparelhos de inspeção de bagagens de um aeroporto do interior paulista. A metodologia empregada para realização deste trabalho foi de fixar pelo período de um mês, quatro dosímetros TLDs, da marca Sapra, dispostos em quatro locais diferentes. Após o período de um mês os dosímetros foram recolhidos e enviados para empresa PRO-RAD prestadora de serviços de monitoração individual contratada pela Universidade do Oeste Paulista - SP. Ao longo de um mês mostra-se que tanto o público quanto ao profissional não atingiram níveis de exposições que requerem atenção especial, quer seja na monitoração individual do trabalhador ou classificação de área. Há também que se dizer que diante dos valores obtidos não há necessidade de implantação de um programa especial de proteção radiológica do que o já implantado pela ANAC (Agência Nacional de Aviação Civil).
\end{abstract}

Palavras-chave: radiação ionizante, aeroporto, proteção radiológica

\section{INVESTIGATION OF THE LEVELS OF IONIZING RADIATION IN THE X-RAY DIAGNOSIS OF AN AIRPORT IN THE INTERIOR OF SÃO PAULO}

\begin{abstract}
Ionizing radiation are electromagnetic waves or particles with high energy capable of producing ionization. Where such interaction with matter waves will trigger a series of ionization. Thus, biological effects may occur to a greater or lesser gravity as the organism or tissue irradiated. This study aimed to assess the levels of ionizing radiation emitted by handsets luggage inspection of an airport in the State of São Paulo. The methodology used for this study was to establish for a period of one month, four dosimeters TLDs, brand Sapra, arranged in four different locations. After the period of one month the dosimeters were collected and sent to the company PRO-RAD individual monitoring service provider contracted by the University of the West of São Paulo. Over a month shows that both the public as to the professional did not reach levels of exhibitions that require special attention, either in individual monitoring of workers or sorting area. It must also be said that in the face of the values obtained there is no need to implement a special program of radiological protection of the already deployed by the ANAC (The National Civil Aviation Agency).

Key words: ionizing radiation, radiological protection, airport
\end{abstract}




\section{INTRODUÇÃO}

A International Commission on Radiological Protection (ICRP), foi estabelecida em 1928, especialmente para as diretrizes de normas de proteção radiológica ionizante para as pessoas potencialmente expostas no cotidiano em seu ambiente de trabalho e para o público em geral ${ }^{1}$.

A portaria 453 do ministério da saúde estabelece as diretrizes básicas de proteção radiológica em radiodiagnóstico médico e odontológico, dispõe sobre o uso dos raios- $x$ diagnósticos em todo território nacional. De acordo com Portaria 453/98 no seu item 2.13 as exposições ocupacionais normais de cada indivíduo, decorrentes de todas as práticas, devem ser controladas de modo que os valores dos limites estabelecidos na Resolução-CNEM n. 12/88 não sejam excedidos. (i) A dose efetiva média anual não deve exceder $20 \mathrm{mSv}$ em nenhum ano. (ii) $\mathrm{A}$ dose equivalente anual não deve exceder 500 mSv para extremidade e 150 mSv para o cristalino ${ }^{2}$

A ciência que estuda as distribuições de doses é conhecida como radiometria ou dosimetria das radiações. A palavra dosimetria é por si só tão explícita quanto é amplo o significado do termo dose. No campo de aplicação da Física Nuclear, a palavra dose assume uma importância muito grande, porque aparece sempre, ou quase sempre, associada à radiação ionizante que, tanto pode beneficiar como prejudicar quem a ela se expõe $e^{3}$. No radiodiagnóstico para a realização de controle usa-se os dosímetros termoluminescentes (TLD).

O dosímetro TLD é um dispositivo composto de cristais nos quais a radiação ionizante cria pares de elétrons e lacunas com propriedades termoluminescentes, quando aquecido emitem luz; esta luz é utilizada para medir doses de radiações ionizantes, como as geradas por aparelhos de Raios-X ou fontes radioativas, cuja intensidade é proporcional á dose da radiação incidente, apresentam-se sob a forma de um volume sensível de um material que consiste de uma massa pequena de um material cristalino dielétrico contendo ativadores convenientes ${ }^{4}$.

Esses ativadores que podem estar presente em quantidades extremamente pequenas criam dois tipos de imperfeições na rede cristalina: armadilhas para elétrons, que capturam e aprisionam os portadores de carga e centros de luminescência. A radiação ionizante, ao interagir com os elétrons, cede energia aos mesmos, que são aprisionadas pelas armadilhas, são liberados fazendo com que percam a energia nos centros de luminescência ${ }^{5}$.

Para algumas matérias as armadilhas resistem bem á temperatura ambiente por períodos de tempo relativamente (maiores que 30 dias), ou seja, só liberam os elétrons e emitem luz após um tratamento. Como o sinal luminoso pode ser proporcional á radiação incidente, esses materiais são bastante convenientes para serem utilizados como dosímetros, principalmente pela sua característica de reutilização antes de apresentarem fadiga expressiva ${ }^{6}$.

Para o leitor de TLD o instrumento utilizado para avaliar a dose em função da luz emitida, é composto de um sistema que faz um aquecimento controlado, de uma válvula fotomultiplicador, que transforma o sinal luminoso em um sinal elétrico amplificado, e de um sistema de processamento e apresentação do sinal ${ }^{7,8}$.

Além dos monitores individuais, as áreas sob controle de proteção radiológica deverão manter os monitores de área para controle regular de radiação do ambiente. As áreas consideradas livres de radiação são aquelas em que a radiação não ultrapassa $1 \mathrm{mSv} / \mathrm{mês}$. As áreas restritas são de acessos controlados, por apresentar níveis de radiação maiores que $1 \mathrm{mSv} / \mathrm{mês,} \mathrm{e}$ são subdivididas em: a) área supervisionada, para os níveis de radiação entre $1 \mathrm{mSv} / \mathrm{mês}$ e 3 $\mathrm{mSv} / \mathrm{mês}$; b) área controlada, se os níveis de radiação forem superiores a $3 \mathrm{mSv} / \mathrm{mês} \mathrm{s}^{4,5,8}$.

O trabalho proposto é justificado pela necessidade de avaliar os níveis de radiação alcançados na inspeção de bagagem de mão de um aeroporto do interior paulista, uma vez que com a ampliação deste setor acarretará a implementação de tecnologias de inspeções que visem a proteção de voos, ambientes e pessoas de modo geral ${ }^{9}$.

Neste estudo objetivou-se aferir os níveis de radiação ionizante emitidas por aparelhos de inspeção de bagagens de mão de um aeroporto do interior paulista. E caso os níveis fossem 
consideráveis realizar uma investigação e proposta de programa de proteção radiológica aos funcionários do aeroporto e público em geral.

\section{METODOLOGIA}

Tendo como objeto de estudo a área de inspeção por Raios-X de um aeroporto do interior de São Paulo serão avaliados níveis de radiação ionizante.

Para realização deste trabalho foram utilizados quatro dosímetros TLDs, da marca Sapra, dispostos da seguinte maneira: um dosímetro será afixado no local por onde os passageiros circulam ao retirarem suas bagagens, outro dosímetro afixado no equipamento de Raios- $X$, um terceiro dosímetro junto ao local onde o funcionário faz as inspeções e um último dosímetro próximo aos guichês de vendas de passagens aéreas, uma vez que neste aeroporto estas duas áreas estão muito próximas.

A figura 1, ilustra a planta da área de inspeção de bagagens e ambientes adjacentes do saguão principal do aeroporto.

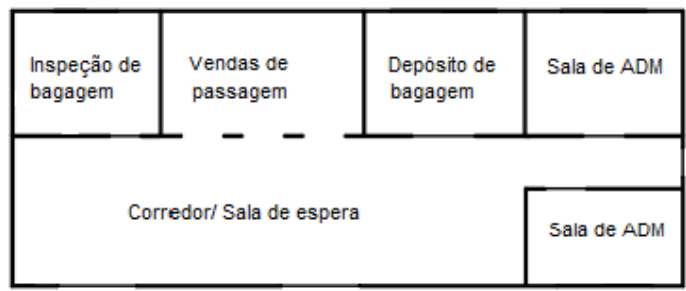

Figura 1. Croqui feito do saguão principal do aeroporto.

Fonte: (Autoria própria)

Os dosímetros ficaram expostos por um período de um mês; após esse tempo eles foram recolhidos enviados à empresa PRO-RAD, empresa de Consultoria em Proteção Radiológica no Brasil, para fornecer as leituras dos níveis de radiação ionizantes registrados.

Especificamente pode-se observar a disposição dos dosimetros, por 30 dias no local, pela figura 2.

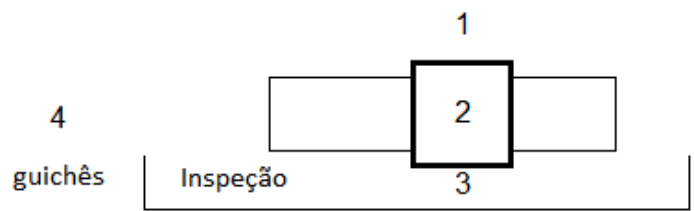

Figura 2. Marcação onde foram colocados os dosímetros Fonte: ( Autoria Própria).

\section{RESULTADOS}

A empresa de Consultoria em Proteção Radiológica no Brasil (PRO-RAD) forneceu o laudo das leituras dos níveis de radiação ionizantes segundo os dosimetros como segue na tabela 1. 
Tabela 1. Leitura dos níveis de radiação.

Fonte: (Autoria Própria)

\begin{tabular}{l|c}
\hline \multicolumn{1}{c|}{ Local de Medida } & $\begin{array}{c}\text { Leitura } \\
\text { (mSv/h) }\end{array}$ \\
\hline 1 - Usuário em geral & 0,00 \\
\hline 2 - Ent/Saída de Bagagem & 0,00 \\
\hline 3 - Profissional & 0,00 \\
\hline 4 - Guichês de vendas & 0,00 \\
\hline
\end{tabular}

\section{CONCLUSÃO}

Obtidos ao longo de um mês apresentado na tabela 1 mostra que tanto público quanto profissionais não atingiram neste período de tempo qualquer valor significativo de radiação ionizante.

Desta forma, fica claro que para este estabelecimento, segundo os níveis de exposições fornecidos, não se requer atenção especial, quer seja na monitoração individual do trabalhador ou em classificação de áreas, bem como não há também necessidade de implantação de um programa especial de proteção radiológica além do já implantado pela ANAC.

\section{REFERÊNCIAS}

1. OKUNO, E. Física Das Radiações. São Paulo. Oficina de textos. 2010.

2. Portaria 453 de 01/06/1998. Diretrizes Básicas De Proteção Radiologia. Ministério da Saúde/BRASIL. 1998.

3. BITELLI, T. Física e dosimetria das radiações. 2ạ. Ed. São Paulo. Editora Atheneu. 2006

4. SOUZA, E. MACEDO. S.P. Correlações Técnicas E Ocupacionais Da Radiologia Intervencionista. Sociedade Brasileira de Angiologia e de Cirurgia Vascular. Rio de Janeiro, v.7, n.4, p.345-345, agosto. 2008.

5. BIRAL, A. R. Radiações Para Médicos, Físicos E Leigos. Florianópolis. Insular. 2002.

6. TILLY Jr, J. G. Física Radiológica. Rio de Janeiro. Guanabara Koogan. 2010.

7. NOBREGA, A.I. Tecnologia Radiológica E Diagnóstico Por Imagem. Volume 2. 5ạ. Ed. São Caetano do Sul, SP. Difusão Editora. 2012.

8. TAUHATA, L. S. Radioproteção e Dosimetria: Fundamentos. 5a. Ed. Rio de Janeiro. 2003.

9. DIMENSTEIN. R. Manual De Proteção Radiológica Aplicada Ao Radioagnóstico. 2ạ. Ed. São Paulo: Senac. 2004. 